1

\title{
Assessing the impact of SIGN 136 on opioid prescribing rates in Scotland: An interrupted time series analysis
}

\author{
Harry L. Hébert ${ }^{\star *}$, Daniel R. Morales ${ }^{1}$, Nicola Torrance ${ }^{2}$, Blair H. Smith ${ }^{1,3}$, Lesley A. Colvin ${ }^{1,3}$
}

1. Division of Population Health and Genomics, School of Medicine, Ninewells Hospital and Medical School, University of Dundee, Dundee, UK.

2. School of Nursing, Midwifery \& Paramedic Practice, Robert Gordon University, Aberdeen, UK.

3. Joint senior authors

*Corresponding author: Harry L. Hébert, Ph.D.

1 Chronic Pain Research Group

2 Division of Population Health and Genomics

Mackenzie Building

14 Ninewells Hospital and Medical School

15 Kirsty Semple Way

16 Dundee

17 DD2 4BF

Tel: $+44(0) 1382383191$

Email: $\underline{\text { h.hebert@dundee.ac.uk }}$

Keywords: Opioid, prescribing, interrupted time series analysis, SIGN 136 


\section{Abstract}

2 Background: Opioids are used to treat patients with chronic pain, but their long-term

3 use is associated with harms. In December 2013, SIGN 136 was published, providing

4 a comprehensive evidence-based guideline for the assessment and management of

5 chronic pain in Scotland

6 Aims: This study aimed to examine the impact of SIGN 136 on opioid prescribing

7 trends and costs across the whole of Scotland.

8 Methods: Opioid prescribing data and average cost per item were obtained from

9 Public Health Scotland. An interrupted time series analysis examined the effects of

10 SIGN 136 publication on the number of items prescribed per 1,000 population per

11 quarter for 29 opioids (or opioid-containing combinations) from 2005 to 2019 inclusive.

12 Exploratory analysis was conducted in NHS Tayside and NHS Fife combined and then

13 up-scaled to all 14 NHS Scotland health boards. A similar approach was also used to

14 assess the effect of SIGN 136 on estimated gross ingredient costs per quarter.

15 Results: At six years post-intervention there was a relative reduction in opioid prescribing of $18.8 \%(95 \% \mathrm{Cl}: 16.0-21.7)$ across Scotland. There was also a relative reduction of $22.8 \%$ (95\%: 14.9-30.1) in gross ingredient cost nationally. Opioid prescribing increased significantly pre-intervention across all $14 \mathrm{NHS}$ Scotland health boards (2.19 items per 1000 population per quarter), followed by a non-significant change in level and a significant negative change in trend post-intervention (-2.69 items per 1000 population per quarter). Similar findings were observed locally in NHS Tayside and NHS Fife.

23 Conclusions: The publication of SIGN 136 coincided with a statistically significant reduction in opioid prescribing rates in Scotland and suggests that changes in clinical policy are having a positive effect on prescribing practices in primary care. These 
medRxiv preprint doi: https://doi.org/10.1101/2021.02.19.21251770; this version posted February 23, 2021. The copyright holder for this preprint

(which was not certified by peer review) is the author/funder, who has granted medRxiv a license to display the preprint in perpetuity.

It is made available under a CC-BY-NC-ND 4.0 International license.

\section{Background}

2 Chronic pain is a common and complex problem, which has a debilitating impact on

3 quality of life (James et al., 2018). The disorder affects approximately $13-50 \%$ of

4 adults in the UK and whilst there is no cure, opioids are commonly used to treat

5 patients with acute and malignant chronic pain (Mills et al., 2019). There is good

6 evidence of their efficacy in this regard, but their effectiveness for long-term chronic

7 pain is less clear (Chou et al., 2015, Moore et al., 2015). Added to this, tolerance can

8 occur in some patients, leading to escalation to higher doses (Dumas and Pollack,

9 2008). Both long-term and high-dose opioid use are associated with adverse events 2018, 2019).

Opioid use has been increasing steadily worldwide with The World Drug Report 2020 estimating that 57.8 million people used opioids globally in 2018 (United Nations, 2020). In particular, the increase in prescribing of opioids in the USA from the late 1990 s to the early 2010s has been well documented (Centers for Disease Control and Prevention (CDC), 2011), with 9.9 million people aged 12 years or over reported to have misused prescription opioids (United Nations, 2020). There are a number of possible explanations for this increase in opioid use, including an ageing population at greater risk of developing chronic pain conditions, changes in prescribing recommendations with increased use for chronic non-cancer pain and more effective marketing from pharmaceutical companies (Smith et al., 2019). This increase in opioid use has given rise to the "opioid epidemic" in the USA and there are concerns a similar situation could be happening in Scotland (Dhalla et al., 2011, Kimber et al., 2019). For example, an 18-fold increase in the rate of strong opioid prescribing was identified in NHS Tayside between 1995 and 2010 (Ruscitto et al., 2015).

In December 2013, the Scottish Intercollegiate Guideline Network (SIGN) in consultation with the National Chronic Pain Steering Group of the Scottish Government published a comprehensive evidence-based guideline for the assessment and management of non-malignant chronic pain (SIGN 136)(Scottish Intercollegiate Guideline Network, 2013). SIGN 136 remains the only comprehensive guideline for chronic pain assessment and management available globally and identified a research gap around understanding rates and effects of opioid prescribing in Scotland. A resulting investigation of national data revealed that prescribing rates of strong opioids doubled in the 10-year period leading up to publication of SIGN 136 (2003-2012) and that approximately $18 \%$ of the population were prescribed an opioid in 2012 (Torrance et al., 2018). This increase appears to be replicated in the rest of the UK (Jani et al., 2020).

Opioid prescribing rates have now become one of NHS Scotland's key National Therapeutic indicators, but to the best of our knowledge, opioid prescribing rates in Scotland have not been formally investigated since the publication of SIGN 136. However, there is anecdotal evidence that they are beginning to fall. Therefore this study aimed to examine the potential impact of SIGN 136 on opioid prescribing trends and costs across the whole of Scotland. 


\section{Methods}

\section{Study Design}

The National Health Service (NHS) in Scotland is administered through 14 regional Health Boards. The study design is an interrupted time series analysis across 15 years of NHS health board level prescribing data on opioid analgesics. Initially, local data were obtained for NHS Tayside and NHS Fife to conduct an exploratory analysis, as the senior authors from the University of Dundee (L.A.C. and B.H.S.) have been involved in developing pathways for chronic pain management based on the SIGN 136 guideline in these areas. Following this preliminary analysis, further national-level data were obtained across all 14 Health Boards, to examine whether the results obtained locally were replicated across the whole of Scotland. As of 2019, the midyear population estimate was 791,020 for NHS Tayside and NHS Fife combined and $5,463,300$ across the whole of Scotland.

The data used in this study contained no patient or prescriber identifiable information. HIC Standard Operational Procedures have been approved by both the Caldicott Guardian and NHS Tayside Research Ethics Committee and review of individual studies is not required provided that only anonymized data are used and HIC Standard Operational Procedures are followed.

\section{Data Source}

Data on opioids prescribed through primary care and dispensed by community pharmacists in Scotland were obtained through the Health Informatics Centre, University of Dundee for NHS Tayside and NHS Fife and from Public Health Scotland for the national-level data (PHS; formerly the Information Services Division), via a bespoke data request. PHS is part of NHS Scotland (https://www.publichealthscotland.scot/) and holds individual-level prescribing data through the Prescribing Information System (PIS), which is a data system, set up in 2009, of prescriptions dispensed and reimbursed in the community, covering approximately 5.3 million residents across Scotland (Alvarez-Madrazo et al., 2016).

\section{Intervention}

The National Chronic Pain Steering Group in conjunction with the Scottish Government and work from key stakeholders, identified a gap in the clinical guidance of managing chronic pain. This work was taken to SIGN with a proposal to produce recommendations on the assessment and management of chronic pain. SIGN develops guidelines based on rigorous systematic reviews and appraisals of evidence specifically for the NHS in Scotland. Subsequently, SIGN 136 was published in December 2013. The opioids section of this guideline (section 5.3 "Opioids), was subsequently updated in August 2019. However for this study we only considered the original 2013 publication as the intervention. This included key recommendations and best practices on safe and effective opioid prescribing (Box 1). This includes 
1 considering the use of "strong opioids" for patients with chronic low back pain or

2 osteoarthritis, with regular review required and specialist referral if there are concerns

3 about rapid-dose escalation or if greater than $180 \mathrm{mg} /$ day (subsequently updated to

4 90mg/day in the 2019 revised edition) morphine equivalent dose is required (Scottish

5 Intercollegiate Guideline Network, 2013). The Scottish Government requires Health

6 Boards to identify areas of concern where they are not meeting SIGN's Key

7 recommendations, so they become important benchmark standards for care. SIGN

8136 has formed the basis of pain service provision and improvement in Scotland since

9 its publication, and is assumed as the intervention in this study.

\section{Outcome}

The primary outcome was the number of opioid items dispensed per quarter per 1000 population. Quarters were defined as January to March (Q1), April to June (Q2), July to September (Q3) and October to December (Q4), inclusive. A list of the 29 drugs included in the study (consisting of single opioids and compound or combination analgesics including an opioid) is given in box 2 . These include drugs found in chapter 4.7.2 ("opioid analgesics") of the British National Formulary (BNF) (Joint Formulary Committee, 2020). The dataset includes all items prescribed through primary care and dispensed in Scotland. Information on items prescribed but not subsequently dispensed is not currently held by PHS. Items prescribed in Scotland and dispensed in England, private prescriptions, hospital and direct supply of medicines to patients (e.g. prescriptions supplied though clinics) were excluded.

The secondary outcome was the gross ingredient cost for opioid items dispensed per quarter.

In the primary analysis, an interrupted time series with segmented regression was used to examine the impact of SIGN 136 on prescribing trends both locally and nationally between Q1 2005 and Q4 2019, inclusive. The segmented regression used the following model:

$$
Y=\beta 0+\beta 1 * \text { Time }+\beta 2 * \text { Intervention }+\beta 3 * \text { Intervention } * \text { Time }
$$

Where $Y$ is the outcome (prescribing rate or cost), $\beta 0$ is the intercept representing the value of the outcome at the start of the study period, $\beta 1$ represents the change in outcome per unit time (quarter) before the intervention, $\beta 2$ represents the immediate step change in level following the intervention and $\beta 3$ represents the change in trend following the intervention (relative to the baseline trend). Time and intervention relate to variables representing the time elapsed since the start of the study period and the pre- or post-study period, respectively.

The intervention was defined as Q4, 2013, providing 36 data points before the intervention and 24 data points after the intervention. 
1 The secondary analysis used a similar approach to examine the impact of SIGN 136

2 on gross ingredient cost nationally between Q1 2005 and Q4 2019, inclusive. Data on

3 the average gross ingredient cost per item for each drug were obtained through the

4 annual publication of prescription cost analysis report from PHS

5 (https://www.isdscotland.org/Health-Topics/Prescribing-and-Medicines/Community-

6 Dispensing/Prescription-Cost-Analysis/). This was multiplied by the number of items

7 for each drug per quarter.

8 For each regression analysis the following were estimated:

$9 \quad-\quad$ the trend before the intervention

- the immediate step change following implementation of the intervention

- the change in trend following implementation of the intervention

12 The effect of the intervention was calculated from the model coefficient estimates by subtracting the expected value of the outcome, had the pre-intervention trend continued, from the observed value of the outcome at quarter 4, 2019. The effects are presented as relative percentage changes and 95\% confidence intervals $(\mathrm{Cl})$ were calculated using model bootstrapping approaches (Zhang et al., 2009). All models were checked for autocorrelation using the Durbin-Watson statistic.

18 All analyses were carried out using the statistical software R (version 4.0.3; R Core

19 Team, 2020). 


\section{Results}

\section{Prescribing Rates}

Between Q1 2005 and Q4 2019, a total of 91,210,542 prescription items were dispensed across Scotland for the 29 drugs included in this study. The most commonly prescribed drugs were co-codamol $(40,099,832$ items; $44.0 \%$ of total), tramadol (14,350,361 items; 15.7\%), co-dydramol (7,430,818 items; $8.1 \%)$, dihydrocodeine $(7,200,128$ items; $7.9 \%)$, methadone $(7,184,903$ items; $7.9 \%)$, morphine $(5,554,778$ items; $6.1 \%)$, oxycodone $(2,717,417$ items; $3.0 \%)$, codeine $(2,297,259$ items; $2.5 \%)$, fentanyl (1,361,855 items; $1.5 \%)$, and buprenorphine $(1,215,554$ items; $1.3 \%)$. Co-codamol and tramadol (54,450,193 items; $59.7 \%)$ had more prescription items dispensed across the study period than the rest of the 27 drugs combined (36,760,349 items; 40.3\%).

In NHS Tayside and NHS Fife combined, the overall number of opioid prescription items rose steadily from 135,045 in Q1 2005 to 214,557 in Q4 2013. Since the publication of SIGN 136, the number of opioid prescriptions has gradually fallen to 210,604 items (Figure 1A). The interrupted time series analysis of this data showed a statistically significant positive trend in the prescribing rate leading up to the intervention (2.17 items per 1,000 population per quarter, 95\% Cl: 1.97, 2.38), followed by an immediate, non-significant fall and a significant negative change in trend following the intervention (-2.68 items per 1,000 population per quarter, $95 \% \mathrm{Cl}$ : $-3.12,-2.25)$. There was a significant negative post-intervention trend $(-0.50$ items per $1,000$ population per quarter, $95 \% \mathrm{Cl}:-0.86,-0.15)$ and at the end of the study period the observed quarterly opioid prescribing rate was estimated to be $20.2 \%$ lower (95\% $\mathrm{Cl}: 17.5,23.1)$ than the expected rate had the pre-intervention trend continued (Table 2A).

Across the whole of Scotland, the number of opioid prescription items also rose steadily from 1,040,276 in Q1 2005 to 1,608,984 in Q4 2013. Since the publication of SIGN 136, the number of opioid prescriptions has gradually fallen to $1,596,240$ items (Figure 1B). The interrupted time series analysis of this data showed a statistically significant positive trend in the prescribing rate before the intervention (2.19 items per $1,000$ population per quarter, $95 \% \mathrm{Cl}: 1.97,2.40)$, followed by an immediate nonsignificant fall, and a significant negative change in trend following the intervention (2.69 items per 1,000 population per quarter, $95 \% \mathrm{Cl}:-42.20,-29.76)$. There was a significant negative post-intervention trend (-0.50 items per 1,000 population per quarter, $95 \% \mathrm{Cl}:-0.88,-0.13$ ) and at the end of the study period the observed quarterly opioid prescribing rate was estimated to be $18.8 \%$ lower $(95 \% \mathrm{Cl}$ : $16.0,21.7)$ than the expected rate had the pre-intervention trend continued (Table $2 \mathrm{~B}$ ).

\section{Costs}

Between Q1 2005 and Q4 2019, the estimated total gross ingredient cost of opioid prescription items dispensed across Scotland for the 29 drugs included in this study was $£ 849,786,655$. The drugs with the highest estimated total gross ingredient cost 
1 were co-codamol (£223,618,648; 26.3\%), oxyxodone (£106,511,546; 12.5\%),

2 methadone $(£ 96,207,292 ; 11.3 \%)$, tramadol $(£ 89,783,312 ; 10.6 \%)$, fentanyl

$3 \quad(£ 75,532,220 ; 8.9 \%)$, co-dydramol (£64,225,466; 7.6\%), morphine $(£ 53,398,259$;

$4 \quad 6.3 \%)$, buprenorphine $(£ 41,016,450 ; 4.8 \%)$, dihydrocodeine $(£ 36,030,814 ; 4.2 \%)$, and

5 buprenorphine and naloxone (£25,796,014; 3.0\%). Co-codamol, oxycodone and

6 methadone $(£ 426,337,486 ; 50.2 \%)$ had a higher estimated gross ingredient cost

7 across the study period than the rest of the 26 drugs combined ( $£ 423,449,169$;

$849.8 \%)$.

9 Across the whole of Scotland, the estimated gross ingredient cost for the 29 drugs

10 rose from $£ 9,722,763$ in Q1 2005 to $£ 14,693,703$ in Q4 2013. Since the publication of

11 SIGN 136, the estimated gross ingredient cost has gradually fallen to $£ 13,735,668$ in

12 Q4 2019 (Figure 1C). The interrupted time series analysis of this data showed a

13 statistically significant positive trend in cost before the intervention ( $£ 78,473$ per

14 quarter, 95\% Cl: 48,653, 108,291), followed by an immediate non-significant rise, and

15 a significant negative change in trend following the intervention ( $£-193,044$ per

16 quarter, 95\% Cl: $-255,438,-130,649)$. There was a significant negative post-

17 intervention trend ( $£-114,571$ per quarter, $95 \% \mathrm{Cl}:-161,969,-67,175)$ and at the end

18 of the study period the observed gross ingredient cost was estimated to be $22.8 \%$

19 lower $(95 \% \mathrm{Cl}: 14.9,30.1)$ than the expected gross ingredient cost had the pre-

20 intervention trend continued (Table 2C). 
medRxiv preprint doi: https://doi.org/10.1101/2021.02.19.21251770; this version posted February 23, 2021. The copyright holder for this preprint

(which was not certified by peer review) is the author/funder, who has granted medRxiv a license to display the preprint in perpetuity.

It is made available under a CC-BY-NC-ND 4.0 International license .

1

2

3

4

5

\section{Discussion}

In this study, we found that the publication of SIGN 136 coincided with a statistically significant reduction of $20.2 \%$ in primary care prescribing of opioids locally in NHS Tayside and NHS Fife combined at the end of the study period. This finding was replicated at a national level, with the intervention coinciding with a statistically significant reduction of $18.8 \%$ in opioid prescribing. Over 90 million prescription items were dispensed for the 29 opioid or opioid combinations across Scotland in the 15year study period. Co-codamol and tramadol were the most prescribed drugs and had more items dispensed than the other 27 drugs combined. Additionally the publication of SIGN 136 was associated with a significant reduction of $22.8 \%$ in the gross ingredient cost of the drugs included in the study, with co-codamol, oxycodone and methadone having the highest costs in the 15-year period and having a higher combined cost than the other 26 drugs. However, caution should be exercised with respect to this model as the plot suggests there could be a non-linear relationship both before and after the intervention (a key assumption of linear regression analysis). This requires further investigation. To the best of our knowledge this is the first study to analyse changes in opioid prescribing costs in Scotland.

The increase in opioid prescribing up to 2013 , both locally and nationally, has been described in previous studies conducted in Scotland. Ruscitto and colleagues identified an 18-fold increase in the rate of strong opioid prescribing in NHS Tayside between 1995-2010 and Torrance and colleagues found that strong opioids doubled from 2003 to 2012 and weak opioids increased by 50\% (Ruscitto et al., 2015, Torrance et al., 2018). However, both of these studies were conducted before the publication of SIGN 136. A more recent study by Jani and colleagues showed similar increases in the UK as a whole with a 30 -fold, 7 -fold and 5 fold increase in oxycodone, tramadol and codeine prescriptions respectively between 2006 and 2017 (Jani et al., 2020). This continuing increase in opioid prescribing across the UK beyond 2013 and the publication of SIGN 136, appears to be in contrast with the results from this Scottish study.

In common with all epidemiological studies, association does not necessarily mean causation and the impact of other interventions and processes cannot be ruled out. SIGN 136 has been influential in driving government policy on chronic pain management and has been incorporated into clinical practice with the publication of the National Prescribing Strategy for Chronic Pain (Scottish Government Effective Prescribing and Therapeutics Branch, 2018), the Royal College of Anaesthetists Quality Improvement Compendium (The Royal College of Anaesthetists, 2020) and the Medicines and Healthcare products Regulatory Agency guidance on the safe use of opioids (Medicines and Healthcare products Regulatory Agency, 2020). Coverage of the ongoing opioid epidemic in the USA and elsewhere in the world through the press is also likely to have raised awareness amongst the general public and patients with chronic pain may have gained a greater understanding of the risks of opioid treatments and other options available. An update to SIGN 136 was also published in August 2019, providing more specific and detailed guidance on opioid prescribing (Scottish Intercollegiate Guideline Network, 2019). The potential impact of this update has yet to be realised and should be the focus of future studies. 
1 A strength of the study is the number of data points available before and after the

2 intervention. We had 36 data points pre-intervention and 24 data points post-

3 intervention, which meant that the study was able to identify a significant change in

4 trend in both the prescribing rate and estimated costs. Another strength of the study is

5 the coverage in community prescribing. GPs account for approximately $95 \%$ of

6 community prescribing and so the dataset that was provided by PHS is a

7 comprehensive representation of the overall state of opioid prescribing in Scotland

8 (Alvarez-Madrazo et al., 2016).

9 A limitation of the PIS database that PHS uses is that it does not currently capture

10 prescriptions that are not dispensed or claimed by a pharmacist in Scotland (Alvarez-

11 Madrazo et al., 2016). However, the proportion of these is likely to be very small.

12 The study was also able to analyse a large number of opioids and opioid combinations

13 and future work will focus on separating the drugs into 'strong' and 'weak' opioids, in

14 line with previous studies.

15 Due to the preliminary nature of this analysis, further work will be conducted to

16 improve the models developed so far. In particular, the effects of age, gender and social deprivation will be explored. Models will also be corrected to take into account seasonality, autocorrelation (the tendency for observations close to each other in time to be more similar than observations further apart in time) and a possible delay in the intervention effect. Scotland. Whilst this effect cannot be definitively linked to the publication of SIGN 136, it at least suggests that changes in clinical and government policy, most of which have been inspired by its publication, are having a positive effect on prescribing practices in primary care. This highlights the importance of providing continued sound clinical advice, based on up-to-date evidence, for safe and effective treatment for chronic pain. This process will continue as further guidelines are published. 
medRxiv preprint doi: https://doi.org/10.1101/2021.02.19.21251770; this version posted February 23, 2021. The copyright holder for this preprint

(which was not certified by peer review) is the author/funder, who has granted medRxiv a license to display the preprint in perpetuity.

It is made available under a CC-BY-NC-ND 4.0 International license .

\section{Acknowledgements}

2 We acknowledge the help and support of Public Health Scotland and the Health

3 Informatics Centre, University of Dundee for managing and supplying the anonymised

4 data.

$6 \quad$ Funding

7 No external financial support was received for this study.

9 Conflict of Interest

10 L.A.C. chaired the Guideline Development Group for the Scottish Intercollegiate

11 Guideline Network publication, "Management of Chronic Pain" to which this paper

12 refers, proposed an update due to changing evidence, and contributed to the update

13 of the opioids section. She has been Vice Chair of SIGN since October 2020 and was

14 a member of the Scottish Government group that developed the Quality Prescribing

15 Strategy for Chronic Pain.

16 B.H.S. was a member of the Guideline Development Group for the Scottish

17 Intercollegiate Guideline Network publication, "Management of Chronic Pain" to which

18 this paper refers. He is the Scottish Government's National Lead Clinician for Chronic

19 Pain (since 2014).

20 D.R.M. is supported by a Wellcome Trust Clinical Research Development Fellowship

21 (Grant 214588/Z/18/Z) and reports grants from the Chief Scientist Office (CSO),

22 Health Data Research UK (HDR-UK) and the National Institute of Health Research

23 (NIHR), outside of the submitted work.

24 H.L.H., and N.T. have no conflicts of interest to disclose. 
medRxiv preprint doi: https://doi.org/10.1101/2021.02.19.21251770; this version posted February 23, 2021. The copyright holder for this preprint

(which was not certified by peer review) is the author/funder, who has granted medRxiv a license to display the preprint in perpetuity.

It is made available under a CC-BY-NC-ND 4.0 International license.

Box 1 - Summary of the original SIGN 136 guideline (2013 edition) intervention for use of opioids in the management of adults with chronic non-malignant pain in non-specialist settings

\section{Key recommendation(s) (based on evidence)}

- Strong opioids should be considered as an option for pain relief for patients with chronic low back pain or osteoarthritis, and only continued if there is ongoing pain relief. Regular review is required.

Other recommendation(s) (based on evidence)

- Patients prescribed opioids should be advised of the likelihood of common side effects such as nausea and constipation.

- It may be necessary to trial more than one opioid sequentially, as both effectiveness and side effects vary between opioids.

- Signs of abuse and addiction should be sought at re-assessment of patients using strong opioids. Routine urine drug testing, pill counts or prescription monitoring should not be used to detect problem use.

- Currently available screening tools should not be relied upon to obtain an accurate prediction of patients at risk of developing problem opioid use before commencing treatment.

- Specialist referral or advice should be considered if there are concerns about rapid-dose escalation with continued unacceptable pain relief, or if $>180 \mathrm{mg} /$ day morphine equivalent dose is required.

Good Practice Points (based on clinical experience of the guideline development group)

- All patients on strong opioids should be assessed regularly for changes in pain relief, side effects and quality of life, with consideration given to a gradual reduction to the lowest effective dose.

- Opioid rotation should be considered for chronic pain that is likely to respond to opioids, if there are problems with efficacy or side effects.

- There should be careful assessment of pre-existing risk factors for developing opioid misuse. In patients where opioid therapy is indicated, but there is an increased risk of iatrogenic opioid misuse, specialist advice should be sought. The minimal effective dose should be used to avoid increased problems of fracture and overdose that may occur on higher doses. 
medRxiv preprint doi: https://doi.org/10.1101/2021.02.19.21251770; this version posted February 23, 2021. The copyright holder for this preprint (which was not certified by peer review) is the author/funder, who has granted medRxiv a license to display the preprint in perpetuity. It is made available under a CC-BY-NC-ND 4.0 International license .

Box 2 - List of opioids (BNF 4.7.2) and opioid-containing combination analgesics included in the study

\begin{tabular}{|c|c|}
\hline 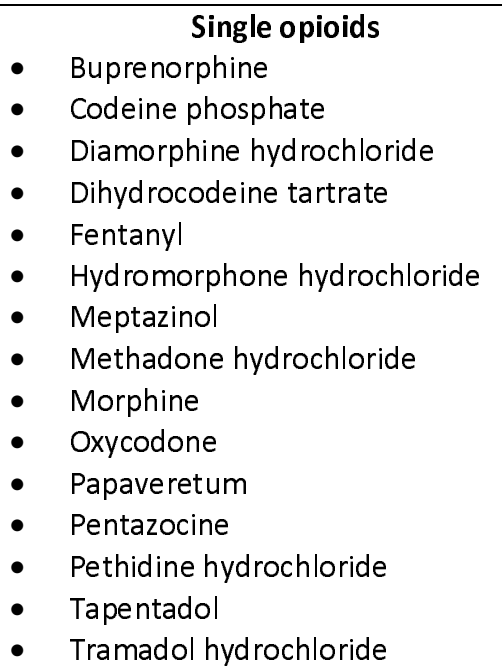 & 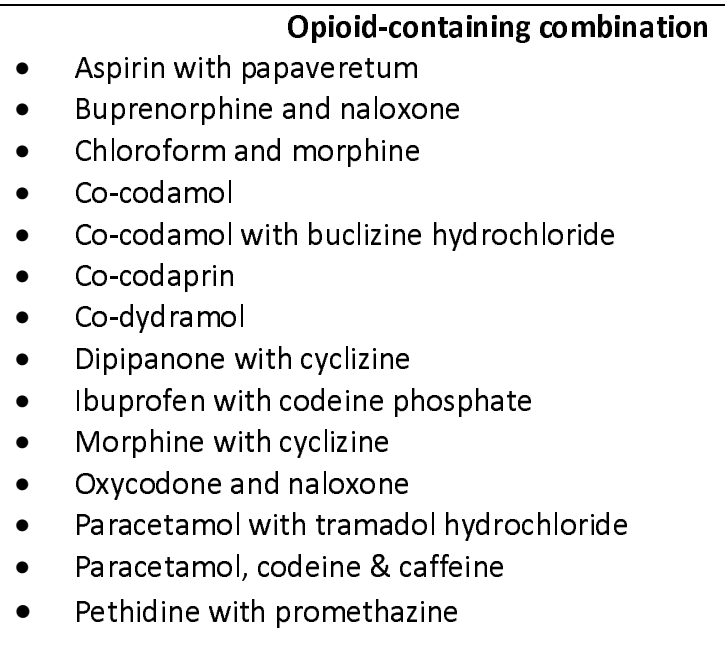 \\
\hline
\end{tabular}




\begin{tabular}{|c|c|c|c|c|c|c|c|c|c|c|c|c|c|c|c|c|}
\hline \multirow{3}{*}{$\begin{array}{l}\text { Mid-year } \\
\text { population } \\
\text { estimate } \\
\text { (n) }\end{array}$} & Region & 2005 & 2006 & 2007 & 2008 & 2009 & 2010 & 2011 & 2012 & 2013 & 2014 & 2015 & 2016 & 2017 & 2018 & 2019 \\
\hline & $\begin{array}{l}\text { A. NHS } \\
\text { Tayside } \\
\text { and NHS } \\
\text { Fife } \\
\end{array}$ & 748,460 & 752,500 & 757,120 & 761,950 & 765,790 & 769,680 & 775,550 & 777,950 & 779,060 & 781,050 & 783,120 & 785,800 & 787,500 & 787,990 & 791,020 \\
\hline & $\begin{array}{l}\text { B. } \\
\text { Scotland }\end{array}$ & $5,110,200$ & $5,133,000$ & $5,170,000$ & $5,202,900$ & $5,231,900$ & $5,262,200$ & $5,299,900$ & $5,313,600$ & $5,327,700$ & $5,347,600$ & $5,373,000$ & $5,404,700$ & $5,424,800$ & $5,438,100$ & $5,463,300$ \\
\hline
\end{tabular}

Table 1 - Mid-year population estimates for NHS Tayside and NHS Fife combined and all 14 NHS Scotland health boards combined 
medRxiv preprint doi: https://doi.org/10.1101/2021.02.19.21251770; this version posted February 23, 2021. The copyright holder for this preprint (which was not certified by peer review) is the author/funder, who has granted medRxiv a license to display the preprint in perpetuity. It is made available under a CC-BY-NC-ND 4.0 International license.

Table 2 - Results of the interrupted time series analysis of opioid prescribing data and costs from NHS Tayside and NHS Fife combined and across Scotland

\begin{tabular}{|c|c|c|c|c|c|c|}
\hline Models & $\begin{array}{l}\text { Intercept, } \beta \\
(95 \% \mathrm{Cl})\end{array}$ & $\begin{array}{l}\text { Pre- } \\
\text { intervention } \\
\text { trend, } \beta \\
(95 \% \mathrm{Cl} / \mathrm{SE})\end{array}$ & $\begin{array}{l}\text { Change in } \\
\text { level, } \beta \\
(95 \% \mathrm{Cl} / \\
\text { SE) }\end{array}$ & $\begin{array}{l}\text { Change in } \\
\text { trend, } \beta \\
(95 \% \mathrm{Cl} / \mathrm{SE})\end{array}$ & $\begin{array}{l}\text { Post- } \\
\text { intervention } \\
\text { trend, } \beta \\
(95 \% \mathrm{Cl} / \mathrm{SE})\end{array}$ & $\begin{array}{l}\text { Relative } \\
\text { Intervention } \\
\text { Effect, \% } \\
(95 \% \mathrm{Cl})^{\mathrm{a}}\end{array}$ \\
\hline \multicolumn{7}{|c|}{ Prescribing Rate } \\
\hline $\begin{array}{l}\text { A. NHS } \\
\text { Tayside and } \\
\text { NHS Fife }\end{array}$ & $\begin{array}{l}197.44 \\
(193.03, \\
201.85)^{\square}\end{array}$ & $\begin{array}{l}2.18 \\
(1.97,2.38 / \\
0.10)^{\square}\end{array}$ & $\begin{array}{l}-1.80 \\
(-8.70,5.10 / \\
3.45)\end{array}$ & $\begin{array}{l}-2.68 \\
(-3.12,-2.25 / \\
0.22)^{0}\end{array}$ & $\begin{array}{l}-0.50 \\
(-0.86,-0.15 / \\
0.17)^{\square}\end{array}$ & $\begin{array}{l}20.2 \\
(17.5-23.1)\end{array}$ \\
\hline B. Scotland & $\begin{array}{l}224.46 \\
(219.83 \\
229.08)^{0}\end{array}$ & $\begin{array}{l}2.19 \\
(1.97,2.40 / \\
0.11)^{0}\end{array}$ & $\begin{array}{l}-2.26 \\
(-9.50,4.98 / \\
3.61)\end{array}$ & $\begin{array}{l}-2.69 \\
(-3.15,-2.23 / \\
0.23)^{0}\end{array}$ & $\begin{array}{l}-0.50 \\
(-0.88,-0.13 / \\
0.18)^{\square}\end{array}$ & $\begin{array}{l}18.8 \\
(16.0-21.7)\end{array}$ \\
\hline \multicolumn{7}{|l|}{ Cost } \\
\hline C. Scotland & $\begin{array}{l}12,443,130 \\
(11,810,455 \\
13,075,803)^{0}\end{array}$ & $\begin{array}{l}78,473 \\
(48,653, \\
108,291 / \\
14,885)^{\square}\end{array}$ & $\begin{array}{l}729,474 \\
(-261,260 \\
1,720,208 / \\
494,566)\end{array}$ & $\begin{array}{l}-193,044 \\
(-255,438,- \\
130,649 / \\
31147)\end{array}$ & $\begin{array}{l}-114,571 \\
(-161,969,- \\
67,175 / \\
22,854)^{\square}\end{array}$ & $\begin{array}{l}22.8 \\
(14.9-30.1)\end{array}$ \\
\hline
\end{tabular}

QP $<0.05$

$\beta$, coefficient; $\mathrm{Cl}$, confidence interval; NHS, National Health Service; SE, standard error ${ }^{a} 95 \%$ Confidence Interval calculated using model bootstrapping 
medRxiv preprint doi: https://doi.org/10.1101/2021.02.19.21251770; this version posted February 23, 2021. The copyright holder for this preprint (which was not certified by peer review) is the author/funder, who has granted medRxiv a license to display the preprint in perpetuity.

\section{It is made available under a CC-BY-NC-ND 4.0 International license .}

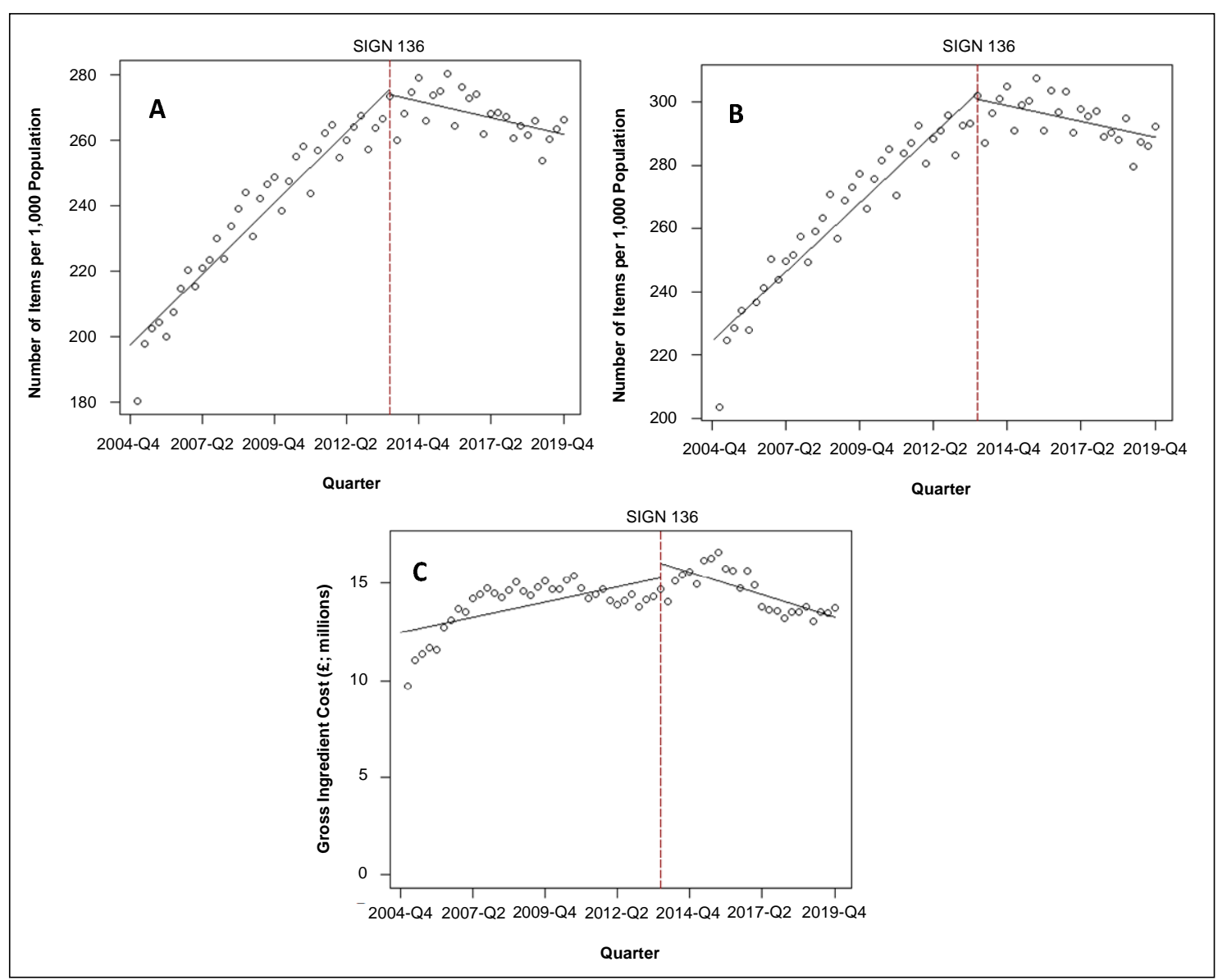

Figure 1 - Plots of the opioid prescribing rate and costs locally and across Scotland from Q1 2005 to Q4 2019. A. The prescribing rate of opioids in NHS Tayside and NHS Fife combined. B. The prescribing rate of opioids in all 14 NHS Scotland health boards. C. The gross ingredient cost of opioids across all 14 NHS Scotland health boards. The red dotted line represents the publication of SIGN 136 (Q4 2013). The solid black lines represents the trend derived from the segmented regression. 
medRxiv preprint doi: https://doi.org/10.1101/2021.02.19.21251770; this version posted February 23, 2021. The copyright holder for this preprint

(which was not certified by peer review) is the author/funder, who has granted medRxiv a license to display the preprint in perpetuity.

It is made available under a CC-BY-NC-ND 4.0 International license .

\section{References}

Alvarez-Madrazo S, McTaggart S, Nangle C, Nicholson E, Bennie M. Data Resource Profile: The Scottish National Prescribing Information System (PIS). Int J Epidemiol 2016;45(3):714-5f.

Centers for Disease Control and Prevention (CDC). Vital signs: overdoses of prescription opioid pain relievers---United States, 1999--2008. MMWR Morb Mortal Wkly Rep 2011;60(43):1487-92.

Chou R, Turner JA, Devine EB, Hansen RN, Sullivan SD, Blazina I, et al. The effectiveness and risks of long-term opioid therapy for chronic pain: a systematic review for a National Institutes of Health Pathways to Prevention Workshop. Ann Intern Med 2015;162(4):276-86.

Dhalla IA, Persaud N, Juurlink DN. Facing up to the prescription opioid crisis. BMJ 2011;343:d5142.

Dumas EO, Pollack GM. Opioid tolerance development: a pharmacokinetic/pharmacodynamic perspective. AAPS J 2008;10(4):537-51.

Higgins $\mathrm{C}$, Smith $\mathrm{BH}$, Matthews K. Incidence of iatrogenic opioid dependence or abuse in patients with pain who were exposed to opioid analgesic therapy: a systematic review and meta-analysis. Br J Anaesth 2018;120(6):1335-44.

Higgins C, Smith BH, Matthews K. Evidence of opioid-induced hyperalgesia in clinical populations after chronic opioid exposure: a systematic review and meta-analysis. Br J Anaesth 2019;122(6):e114-e26.

James SL, Abate D, Abate KH, Abay SM, Abbafati C, Abbasi N, et al. Global, regional, and national incidence, prevalence, and years lived with disability for 354 diseases and injuries for 195 countries and territories, 1990-2017: a systematic analysis for the Global Burden of Disease Study 2017. Lancet 2018;392(10159):1789-858.

Jani M, Birlie Yimer B, Sheppard T, Lunt M, Dixon WG. Time trends and prescribing patterns of opioid drugs in UK primary care patients with non-cancer pain: A retrospective cohort study. PLoS Med 2020;17(10):e1003270.

Joint Formulary Committee. British National Formulary (online) London: BMJ Group and Pharmaceutical Press. 2020. http://www.medicinescomplete.com

Kimber J, Hickman M, Strang J, Thomas K, Hutchinson S. Rising opioid-related deaths in England and Scotland must be recognised as a public health crisis. Lancet Psychiatry 2019;6(8):639-40.

Medicines and Healthcare products Regulatory Agency. Opioids: risk of dependence and addiction. 2020. https://www.gov.uk/drug-safety-update/opioids-risk-ofdependence-and-addiction

Mills SEE, Nicolson KP, Smith BH. Chronic pain: a review of its epidemiology and associated factors in population-based studies. Br J Anaesth 2019;123(2):e273-e83.

Moore RA, Derry S, Aldington D, Wiffen PJ. Adverse events associated with single dose oral analgesics for acute postoperative pain in adults - an overview of Cochrane reviews. Cochrane Database Syst Rev 2015;2015(10):Cd011407.

$\mathrm{R}$ Core Team. R: A language and environment for statistical computing. $R$ Foundation for Statistical Computing, Vienna, Austria. 2020. https://www.Rproject.org/

Ruscitto A, Smith BH, Guthrie B. Changes in opioid and other analgesic use 19952010: repeated cross-sectional analysis of dispensed prescribing for a large geographical population in Scotland. Eur J Pain 2015;19(1):59-66. 
Scottish Government Effective Prescribing and Therapeutics Branch. The Scottish Chronic Pain Prescribing Strategy. 2018.

https://www.therapeutics.scot.nhs.uk/pain/

Scottish Intercollegiate Guideline Network. SIGN 136. Management of chronic pain: a national clinical guideline. 2013. https://www.sign.ac.uk/assets/sign136.pdf

Scottish Intercollegiate Guideline Network. SIGN 136: management of chronic pain: a national clinical guideline (revised edition). 2019. https://www.sign.ac.uk/media/1108/sign136_2019.pdf

Smith $\mathrm{BH}$, Fletcher EH, Colvin LA. Opioid prescribing is rising in many countries. BMJ 2019;367:15823.

The Royal College of Anaesthetists. Raising the Standards: RCoA quality improvement compendium. 2020.

https://rcoa.ac.uk/sites/default/files/documents/2020-

08/21075\%20RCoA\%20Audit\%20Recipe\%20Book_Combined_Final_25.08.2 020_0.pdf

Torrance N, Mansoor R, Wang H, Gilbert S, Macfarlane GJ, Serpell M, et al. Association of opioid prescribing practices with chronic pain and benzodiazepine co-prescription: a primary care data linkage study. $\mathrm{Br} \mathrm{J}$ Anaesth 2018;120(6):1345-55.

United Nations. World Drug Report 2020. 2020. https://wdr.unodc.org/wdr2020/

Zhang F, Wagner AK, Soumerai SB, Ross-Degnan D. Methods for estimating confidence intervals in interrupted time series analyses of health interventions. J Clin Epidemiol 2009;62(2):143-8. 